\title{
COMPETIÇÃO DE BASE E A FORMAÇÃO DE JOVENS ATLETAS NA PERSPECTIVA DE TREINADORES DE ELITE NO HANDEBOL
}

\author{
Tathyane Krahenbühl \\ Universidade Federal de Goiá, Goiânia, Goiás, Brasil. \\ Larissa Rafaela Galatti \\ Universidade Estadual de Campinas, Campinas, São Paulo, Brasil. \\ Alcides José Scaglia \\ Universidade Estadual de Campinas, Campinas, São Paulo, Brasil. \\ Lucas Leonardo \\ Universidade Estadual de Campinas, Campinas, São Paulo, Brasil.
}

\begin{abstract}
Resumo
O esporte e a competição são inseparáveis, estão presentes na vida dos jovens que praticam esportes e, por isso, é necessário criar ambientes favoráveis ao desenvolvimento desses indivíduos. O objetivo desta pesquisa foi conhecer as percepções dos treinadores de handebol de elite quanto aos aspectos da promoção de competições para jovens. Quatro treinadores de elite foram entrevistados e, a partir da análise qualitativa das entrevistas, foi possível dividir os resultados em quatro categorias: a) Adaptações para competições; b) Utilização do sistema defensivo individual; c) Papel do treinador; e d) Vitória como foco nas competições de base. Foram apresentadas necessidades e sugestões para criar um ambiente competitivo favorável e pressupostos à atuação do treinador de base.
\end{abstract}

Palavras-chave: Treinadores. Formação Esportiva. Competição. Handebol.

\section{YOUTH COMPETITION AND THE TRAINING OF YOUNG ATHLETES FROM THE PERSPECTIVE OF ELITE HANDBALL COACHES}

\begin{abstract}
Sport and competition are inseparable and are present in the lives of young people who play sports and therefore it is necessary to create environments conducive to the development of them. The objective of this research was to know the perceptions of elite handball coaches regarding the premises associated with the promotion of youth competitions. Four elite coaches were interviewed and, from the qualitative analyses, it was possible to divide the results into four categories: a) Adaptations for competitions; b) Use of the individual defensive system; c) Role of the coach; and d) Victory as a focus on young competitions. Requirements and suggestions were presented to create a favourable competitive environment, in addition to assumptions the performance of the young coaches.
\end{abstract}

Keywords: Coaches. Sports Training. Sporting Competition. Handball. 


\title{
COMPETICIÓN DE BASE Y LA FORMACIÓN DE JÓVENES ATLETAS A PARTIR DE LAS PERSPECTIVAS DE LOS ENTRENADORES DE ÉLITE EN EL BALON- MANO
}

\begin{abstract}
Resume:
El deporte y la competición son inseparables y están presentes en la vida de los jóvenes que practican deportes y, por eso, es necesario crear ambientes favorables al desarrollo de esos individuos. El objetivo de esta investigación fue conocer las percepciones de los entrenadores de balonmano de elite como las premisas asociadas a competiciones para jóvenes. Cuatro entrenadores fueron entrevistados y fue posible dividir los resultados en cuatro categorías: a) Adaptaciones para competiciones; b) utilización del sistema defensivo individual; c) Papel del entrenador; y d) Victoria como foco en las competiciones de base. Se presentaron necesidades y sugerencias para crear un ambiente competitivo favorable, además de presupuestos para la actuación del entrenador de base.
\end{abstract}

Palabras clave: Entrenadores. Formación deportiva. Competición. Balonmano.

\section{Introdução}

O esporte é considerado um dos fenômenos socioculturais de maior relevância para a sociedade contemporânea devido à sua disseminação em vários setores da sociedade e pela diversidade de significados da sua prática. Tal fenômeno engloba diversas práticas humanas, compostas por regras regulamentadas e institucionalizadas, muitas vezes direcionadas para a competição manifestada pelo confronto entre equipes/sujeitos ou pela comparação dos desempenhos (MARQUES; ALMEIDA; GUTIERREZ, 2007).

Por ser a competição esportiva uma manifestação específica do pleno ato de jogar e por ser o jogo cada vez mais valorizado como um elemento fundamental para a organização de um ambiente de ensino, aprendizagem e treinamento em esportes coletivos (LEONARDO; SCAGLIA; REVERDITO, 2009; SCAGLIA; REVERDITO; GALATTI, 2013; SCAGLIA, 2017), entendemos que competir justifica-se como um ambiente de aprendizagem por excelência, logo, a oportunidade de prática competitiva não pode ser negligenciada dentro de programas esportivos.

Tratando especificamente do ambiente competitivo de jovens, torna-se necessário o devido redimensionamento de suas metas para que seu potencial pedagógico seja alcançado (WIERSMA, 2005), sendo necessária a elaboração de estratégias diante da competição que garantam a facilitação da aprendizagem de elementos tático-técnicos, a promoção de valores para a vida, tais como a inclusão e a participação, de modo que essas modificações alinhem-se também às etapas de desenvolvimento físico, social e psicológico do jovem (CÔTÉ; LIDOR; HACKFORT, 2009; ENGEBRETSEN et al., 2010; BERGERON et al., 2015).

A competição deverá ser mediada por procedimentos pedagógicos adequados que promovam a formação de uma base multifuncional, evitando a especialização precoce, sustentada na diferenciação das propostas competitivas tipicamente oferecidas aos adultos (MILISTETD et al., 2008). A referida necessidade de modificação do cenário competitivo infantojuvenil tem fomentado recentes investigações sobre o tema (BROWNE; CARLSON; HASTIE, 2004; BURTON; GILLHAM; HAMMERMEISTER, 2011; MILISTETD et al., 2014; THOMAS; WILSON, 2015; ELLIOTT; PILL, 2016; LEONARDO; SCAGLIA, 2018b).

Essas investigações apresentam pressupostos para uma prática esportiva que se afaste dos processos reguladores de busca excessiva pelo rendimento esportivo em idades muito precoces, características típicas do esporte de elite e, que se não forem superadas, podem envolver os jovens em competições esportivas inadequadas às suas demandas, necessidades e 
possibilidades, fatores que podem implicar em prejuízos no seu envolvimento durante a prática esportiva (FRASER-THOMAS; CÔTÉ; DEAKIN, 2008; CHOI; JOHNSON; KIM, 2014; CRANE; TEMPLE, 2015; CÔTÉ; HANCOCK, 2016).

Uma das modalidades esportivas que historicamente tenta se ajustar ao público jovem é o handebol. Especificamente no território brasileiro estudos têm evidenciado a existência de modificações aplicadas às categorias sub-12 e sub-14 (ARENA; BÖHME, 2008; MILISTETD et al., 2014; MENEZES; MARQUES; NUNOMURA, 2015; LEONARDO; SCAGLIA, 2018a; LEONARDO; SCAGLIA, 2018b), destacando-se a obrigatoriedade do uso do sistema defensivo individual em partes dos jogos oficiais, como acontece em competições da Federação Paulista de Handebol e nos Jogos Escolares Brasileiros (LEONARDO; SCAGLIA, 2018a, LEONARDO; SCAGLIA, 2018b; COB, 2018), evidenciando-os como ambientes competitivos modificados e preocupados com a formação de atletas em longo prazo.

Os treinadores que estão à frente das seleções nacionais brasileiras da categoria adulta recebem o egresso do processo iniciado em ambientes competitivos modificados, porém, pouco se sabe sobre suas perspectivas acerca da importância e pertinência dos procedimentos pedagógicos adotados no ambiente competitivo dos jovens praticantes de handebol, tendo em vista os frutos a serem colhidos durante a etapa do alto rendimento esportivo, no qual estão inseridos.

Diante do exposto, este estudo visa apresentar quais são as percepções dos treinadores de elite do handebol brasileiro quanto aos pressupostos associados à promoção de competições destinadas ao público infanto-juvenil.

Ao darmos voz para que treinadores de handebol de elite opinem sobre o papel da competição de jovens, apresentamos a percepção desses treinadores acerca de como a prática competitiva se insere no contexto da formação esportiva do jovem atleta de handebol e esperamos que essas opiniões possam balizar e qualificar o debate sobre esses modelos competitivos, no sentido de contribuir para o processo de formação em longo prazo de atletas de alto desempenho na modalidade.

\section{Procedimentos Metodológicos}

\section{Caracterização da Pesquisa e Participantes}

Esta é uma pesquisa de caráter qualitativo, cujos dados foram coletados a partir de uma entrevista semiestruturada, realizada pela primeira pesquisadora nos ambientes de prática profissional dos treinadores entrevistados.

Foram entrevistados quatro treinadores (T1, T2, T3 e T4), com experiência em cam-

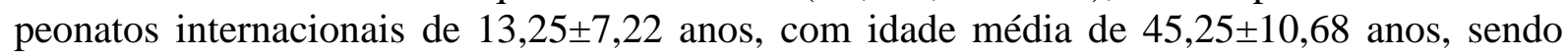
três brasileiros e um espanhol (tabela 1). Os critérios de seleção dos participantes foram a participação na comissão técnica da seleção brasileira de handebol Junior ou Adulta, no naipe feminino, com atuação no último ciclo olímpico (2013-2016) ou no atual (2017-2020). A opção por elegermos membros das equipes femininas de handebol deu-se pela facilidade de acesso a esses treinadores e também pela relevância que o handebol feminino brasileiro possui em âmbito internacional, devido à sua hegemonia nas categorias de base e adulta nas Américas, à conquista de um título mundial da modalidade e à eleição de duas atletas como as melhores jogadoras do mundo.

Todos os treinadores entrevistados têm formação em Educação Física ou em curso de formação no ensino superior correspondente em cenário internacional. Apenas um treinador não tem pós-graduação, sendo que os demais declararam ter pós-graduação na área esportiva (treinamento, gestão ou ciência aplicada ao esporte). 
Todos os entrevistados assinaram um Termo de Consentimento Livre e Esclarecido (TCLE), aprovado pelo Comitê de Ética em Pesquisa da Universidade Estadual de Campinas sob o número 57799916.1.0000.5404.

Tabela 1. Caracterização dos treinadores participantes

\begin{tabular}{cccccc}
\hline Treinador & $\begin{array}{c}\text { Idade } \\
\text { (anos) }\end{array}$ & Sexo & $\begin{array}{c}\text { Ciclos Olím- } \\
\text { picos }\end{array}$ & $\begin{array}{c}\text { Função exercida durante o } \\
\text { Ciclo Olímpico }\end{array}$ & $\begin{array}{c}\text { Principal conquista em } \\
\text { âmbito Internacional }\end{array}$ \\
\hline T1 & 36 & Masculino & $\begin{array}{c}2013-2016 \\
2013-2016\end{array}$ & Treinador Auxiliar & Campeão Mundial Adulto \\
T2 & 37 & Masculino & $\begin{array}{c}\text { Treinador Auxiliar } \\
\text { Campeão Mundial Adulto }\end{array}$ & Bronze nos Jogos Olímpicos \\
T3 & 56 & Masculino & $2017-2020$ & Treinador Principal & $\begin{array}{c}\text { dendres } \\
\text { T4 }\end{array}$ \\
\hline
\end{tabular}

Instrumentos

As perguntas que constituíram nosso roteiro de entrevistas foram: a) "Como devem ser organizadas as competições em categorias de base (sub-12, sub-14 e sub-16)?" e b) "Em competições de base, qual deve ser o papel desempenhado pelo treinador?". Permitimos que novas considerações relacionadas ao problema central de nosso estudo emergissem das entrevistas, fomentando, nesses casos, novos questionamentos de modo particular a cada um dos entrevistados.

As entrevistas foram gravadas e transcritas utilizando a transcrição textual suave, em que a transcrição é feita palavra por palavra, limpando do texto expressões e palavras não condizentes, tornando o texto coerente e simples de entender (MAYRING, 2014).

\section{Análise dos dados}

A análise dos dados foi realizada por dois pesquisadores com experiência como professor ou treinador de handebol, de 13,5 $\pm 0,7$ anos. Segundo Mayring (2014), a interferência do pesquisador sobre o texto bruto é respaldada pelos seus conhecimentos prévios sobre o tema de pesquisa (sustentados por suas impressões pessoais e pela sustentação teórica norteadora do estudo). Isso garante a possibilidade de sintetizar as informações através de processos de redução e sintetização, com prevalência das informações em sua qualidade e não pela quantidade de palavras presentes no texto, tendo como principal cuidado a manutenção das ideias centrais dessas mensagens.

Após transcritas as entrevistas, foi realizada a Análise Qualitativa de Conteúdo, proposta por Mayring (2014). O processo de análise qualitativa do conteúdo é iniciado pelas análises de cada entrevista individualmente, sendo realizada para cada uma a primeira redução de dados, na qual os materiais são lidos e parafraseados.

Parafrasear, segundo Mayring (2014), é uma forma de redução que permite que as mensagens essenciais do texto original sejam reproduzidas num texto mais enxuto através de processos de generalização. As frases semelhantes contidas são resumidas numa única paráfrase que permite diminuir substancialmente a quantidade de informação.

Após essa etapa, realizamos a segunda redução de dados, utilizando os processos de construção e integração, que permitiram unificar as paráfrases dos entrevistados que eram semelhantes em seu núcleo numa só frase que contivesse as mesmas ideias. Com esses procedimentos, as fontes de informação passaram a ser representadas por "Resposta-Síntese" (RS), que serão numeradas e apresentadas ao longo do texto. Ao fim de cada uma, destacamos em parênteses os treinadores que emitiram opiniões que ajudaram na elaboração dessas respostas. 


\section{Resultados e Discussão}

Percebemos nos discursos dos treinadores de elite do handebol brasileiro uma preocupação com a formação dos jovens jogadores por meio da participação competitiva, cujas opiniões puderam ser categorizadas em quatro principais perspectivas: a) Adaptações para as competições nas categorias de base; b) Uso do sistema defensivo individual nas categorias de base; c) Papel do treinador nas categorias de base; d) Vitória como foco nas competições de base. Apresentaremos a seguir os resultados e discussões separadamente para cada uma dessas categorias.

\section{Adaptações para as competições nas categorias de base}

Essa categoria foi elaborada a partir dos discursos dos treinadores que, ao entender que a competição nas categorias de base deve ser pensada de forma diferente, colocaram possíveis adaptações no cenário competitivo do handebol. Os treinadores apresentaram em suas entrevistas uma série de ideias relacionadas à promoção de modificações, que, segundo suas opiniões, são apontadas como relevantes para as partidas oficiais.

RS1: As competições para categorias menores devem ser mais pontuais, com sistema de pontuação que evite placares com grandes diferenças. As regras devem ser mais flexíveis, assim como o número de jogadores e o espaço do jogo. As defesas mistas devem ser restringidas e todos devem jogar, tornando o jogo mais fácil e divertido $(\mathrm{T} 3, \mathrm{~T} 4)$.

Um dos apontamentos colocados está na ideia de flexibilização das regras com a finalidade de tornar o jogo mais fácil e divertido para os jogadores mais novos, tornando-o mais atrativo. Entre os exemplos citados, consta a modificação do sistema de computar pontos com placar contínuo, o que pode gerar placares com grandes diferenças na pontuação.

Em específico, T4 apresenta como proposta a utilização do sistema de sets como uma forma de evitar que equipes iniciantes sejam desmotivadas frente a placares com grandes diferenças. Acerca desse assunto, Burton, Gillham e Hammermeister (2011) destacam que placares elásticos podem contribuir negativamente para que metas de engajamento do jovem sejam atingidas, compactuando com a visão dos treinadores.

Os treinadores também apontam importantes reflexões sobre o modelo de organização dessas competições, questionando a utilização de competições de temporadas muito longas, aproximando-se das recomendações de Cotê e Hancock (2016), que indicam que as competições para jovens devem se estender por cerca de três ou quatro meses, atingindo, no máximo, temporadas de seis meses.

Os autores também recomendam que no período de experimentação esportiva (dos 8 aos 12 anos de idade) as competições devem ser disputadas regionalmente, diminuindo a necessidade de viagens longas (COTÊ; HANCOCK, 2016).

Também foi apontada pelos entrevistados a possibilidade de flexibilização com relação ao número de jogadores e ao tamanho da quadra, modificações estruturais que se associam com importantes metas de engajamento, como a ampliação das oportunidades de participação e pontuação no jogo (BURTON; GILLHAM; HAMMERMEISTER, 2011), aspectos diretamente associados com maior prazer na prática do handebol para o público jovem (GARCÍA-ÂNGULO; ORTEGA; MENDOZA, 2015).

Fazer jogos reduzidos de handebol, respeitando as regras e a tática geral do jogo, mas simplificando a complexidade de ações, é uma ideia que vai ao encontro de concepções como do "Teaching Games for Understanding" (TGfU), que toma como base a compreensão do 
jogo a partir de diferentes formas de jogar, principalmente a partir dos jogos reduzidos, estimulando o aprendizado tático e a tomada de decisão (WERNER; THORPE; BUNKER, 1996).

As opiniões dos entrevistados também se aproximam das considerações colocadas por Estriga e Moreira (2013), que apresentam em seu trabalho a preocupação em estruturar um modelo processual de aprendizagem do handebol, dividindo as etapas de aprendizagens em quatro níveis, compostas por um modelo de ensino que ajusta as estruturas e equipamentos por meio de seis diferentes formas de jogo, que partem de espaços e número de jogadores reduzidos para chegar ao jogo formal de $7 \times 7$ ao longo do tempo.

A ideia de jogo reduzido é coerente com os momentos de aprendizagem desses jogadores, pois diversificar os espaços, orientando-os de acordo com as habilidades específicas para o nível de compreensão do jogo, é uma ferramenta para o desenvolvimento desses jovens. Espaços menores auxiliam nas ações de retomada de bola (interceptação), atuação sobre pressão (dissuasão e flutuação), controle físico e ocupação de espaços para impedir o avanço do adversário, proporcionando a participação do jogador com maior frequência nas situações do jogo (KRAHENBÜHL; LEONARDO, 2018).

Além disso, foi apontada a importância de oportunizar a vivência nas diversas posições, incluindo a de goleiro, como um diferencial nas competições de jovens.

RS2: Nas competições sub-12 e sub-14 todos os jogadores devem participar do jogo e deveriam passar pela posição de goleiro, pois não há como definir essa posição nessa idade (T3, T4).

Outra indicação foi a proibição de defesas mistas, condição em que os jogadores mais fortes ou mais habilidosos, seja pela questão de entendimento do jogo ou pela questão maturacional, são impedidos de jogar por serem marcados de maneira especial, impedindo que a participação na competição se configure efetivamente em um momento de evolução para esses jogadores, limitando a oportunidade de jogar e aprender.

Uma vez que a competição é um ambiente que pode contribuir para o processo de ensino-aprendizagem dos jovens atletas, deve ser oportunizado para que todos os jogadores participem das partidas por tempos bem distribuídos. No ambiente competitivo, a maior oportunidade de participação nas partidas pode se caracterizar como maior exposição às oportunidades de aprendizagem (LEONARDO et al., 2018).

Esse apontamento parece estar relacionado ao fato de que as decisões dos treinadores de base na escolha de jogadores mais talentosos são influenciadas, principalmente, pela maturação precoce. Por vezes, reduz a atenção necessária aos atletas que amadurecem tardiamente e que em pouco tempo podem se recuperar do atraso em relação aos seus colegas. Assim, a percepção de rendimento causada pelas vantagens de maturação e que são apenas momentâneas, possibilita que os jogadores mais desenvolvidos tenham maiores oportunidades de aprendizagem nas competições (MATTHYS et al., 2012; LEONARDO et al., 2018).

\section{Uso do sistema defensivo individual nas categorias de base}

A obrigatoriedade do uso do sistema defensivo individual nas categorias de base no handebol é uma adaptação que vem ocorrendo com frequência nos últimos anos em algumas competições sub-12 e sub-14 (LEONARDO; SCAGLIA, 2018a), assim como nos Jogos Escolares da Juventude, que também colocam a obrigatoriedade do uso do sistema individual ou de sistemas abertos para as categorias menores (COB, 2018).

Essa obrigatoriedade do uso do sistema defensivo individual ou de sistemas defensivos abertos (em duas ou mais linhas) em detrimento das defesas mistas é tema de estudos com categorias de base no handebol (MENEZES, 2010; MENEZES; REIS; TOURINHO-FILHO, 
2015, LEONARDO; SCAGLIA, 2018b) e presente nas concepções dos treinadores entrevistados.

Percebemos, durante as entrevistas, a recorrente preocupação dos treinadores com a utilização dos sistemas defensivos abertos para a elaboração de competições adaptadas aos jovens atletas. Especificamente em relação ao uso do sistema defensivo individual, são apresentados pontos positivos e negativos acerca de sua importância para estas categorias:

RS3: O sistema defensivo individual ou defesas abertas são bons para trabalhar a motricidade e o aprendizado de procedimentos táticos ofensivos e defensivos na formação, desenvolver ações de 1x1, dar maior mobilidade e autonomia ao jogador (T1, T3, T4)

RS4: O sistema defensivo individual tem desvantagens ao não desenvolver os arremessos de nove metros e ter menos passes e continuidade (T1, T4).

Entre os pontos positivos, as ações de 1x1 devem ser priorizadas nessa faixa etária, principalmente no sub-12, proporcionando maior mobilidade dos jovens jogadores, além de melhor aprendizado de ações técnicas e táticas individuais e grupais.

O sistema defensivo individual traz benefícios na formação desses jogadores, pois possibilita as ações individuais defensivas, estimula as tomadas de decisão dos atacantes em situações de desmarques e fintas (KRAHENBÜHL; LEONARDO, 2018) e está relacionada ao entendimento da lógica do jogo nas faixas etárias das categorias mirim e infantil e de sua importância na formação do jogador para o correto trabalho defensivo (MENEZES; REIS; TOURINHO-FILHO, 2015).

O ensino da marcação individual é uma importante ferramenta pedagógica utilizada na iniciação ao handebol devido às suas características de dinamismo, grande exigência de participação dos jogadores nas diversas condutas táticas e técnicas defensivas individuais, que são necessárias em todos os sistemas defensivos (KRAHENBÜHL; LEONARDO, 2018).

Contudo, apesar de serem favoráveis ao uso do sistema individual nas categorias de base, alguns pontos negativos foram citados pelos treinadores T1 e T4, por exemplo, a diminuição na frequência de arremessos de longa distância, como os arremessos de nove metros, ou a pouca continuidade de passes, como apontado especificamente pelo T1, e que vem prejudicando, segundo a sua opinião, a qualidade técnica dos jogadores brasileiros em relação a esses fundamentos.

Entretanto, como apontado pelo T4, essas condições podem ser minimizadas pelo treinamento e, ao longo do desenvolvimento dos jogadores, que, com o avançar da idade, ficarão mais fortes e habilidosos para evoluir nessas ações motoras.

Papel do treinador nas categorias de base

Os entrevistados também manifestaram opiniões relacionadas ao papel do treinador nas categorias de formação, cujas condutas devem focar o aprendizado e o desenvolvimento dos jovens jogadores, visando ao aperfeiçoamento e à evolução dos atletas.

RS5: O treinador deve encantar os jogadores, ter comprometimento com a aprendizagem e com ambiente de ensino diversificado, criativo, planificado. Sua atuação deve ser independente do resultado do jogo, ter consciência da sua ação pedagógica, possibilitando que todos participem do jogo para aprender e colocar em prática o que foi ensinado nos treinos (T2, T3, T4).

Os entrevistados acreditam que o ambiente de treinamento deve ser diversificado, criativo e planificado e que a competição é o momento em que os jovens jogadores podem colocar em prática todo o conteúdo que lhes foi ensinado, enfatizando que o resultado do jogo é menos importante do que as oportunidades vivenciadas no ambiente competitivo. 
Paralelamente a isso, de maneira específica, T3 afirma que os jogadores da categoria sub-16 já devem ser questionados quanto ao resultado do jogo como forma de entenderem o seu processo de desenvolvimento enquanto atletas, embora para o treinador esse ainda não seja o foco de sua atuação.

Essas opiniões convergem com os pressupostos competitivos apresentados pelo Modelo de Desenvolvimento e Participação Esportiva (CÔTÉ; FRASER-THOMAS, 2007), que propõe que apenas a partir do período de investimento (a partir dos 16 anos de idade) seja o momento em que os resultados competitivos passem a ser mais exigidos, em função de uma via de formação para o desempenho esportivo.

Além disso, as relações estabelecidas entre o treinador e a família diante da competição são capazes de trazer influências sobre como o jovem lida com os valores aprendidos durante a competição esportiva (WIERSMA, 2005; PALOU et al., 2013), aspecto também relatado por T4, quando retrata a importância do envolvimento dos pais nas competições de base, mediante o prévio alinhamento de suas concepções com as do treinador dessas categorias.

Segundo Wiersma (2005), torna-se fundamental para a proposição de um clima competitivo mais ajustado ao desenvolvimento do jovem que, em níveis distintos, sejam ofertadas diferentes metas competitivas, sendo necessárias adaptações e modificações desse cenário, de modo que, nas etapas de formação, competir alinhe-se ao desenvolvimento de competências, antes de sustentar a busca de resultados expressivos.

A partir da conscientização de que nas categorias de formação o papel da competição não se limita apenas à conquista de resultados, mas que também se associa ao desenvolvimento de valores para a vida, familiares passam a incentivar a participação e permanência de seus filhos na prática esportiva e competitiva (CÔTÉ; HAY, 2002; CÔTÉ; FRASER-THOMAS, 2007), pois os pais conferem um valor educacional ao esporte por ser potencialmente benéfico para seus filhos (DOMINGUES; GONÇALVES, 2013).

\section{Vitória como foco nas competições de base}

Uma das grandes questões levantadas por todos os treinadores entrevistados foi a necessidade de vitória dos treinadores das categorias de base. Os treinadores entrevistados entendem que nessas categorias a relevância de vencer ou perder uma partida deve ser secundária.

Contudo, percebem que a valorização dada à vitória é uma das questões que mais interfere nas categorias de base, muitas vezes atrapalhando até mesmo as adaptações colocadas para a formação dos jovens jogadores.

RS6: A adaptação da regra depende da consciência pedagógica do treinador. Não adianta colocar regras que não serão respeitadas. Muitos treinadores são cobrados pelos resultados, fazendo com que não coloquem todos os jogadores na partida, elaborando jogadas complexas para a categoria e que não irão desenvolver o atleta de maneira adequada (T1, T2).

RS7: O principal problema na competição de base é que os treinadores focam na vitória do campeonato e não na formação dos atletas. O sistema defensivo individual é prejudicado pelo imediatismo pela vitória dos treinadores, que, mesmo com as regras adaptadas, desenvolvem formas de burlar as regras para vencer (T1, T2, T3 T4).

Para que crianças e jovens permaneçam na prática esportiva são fatores mais importantes a imparcialidade, a participação e o desenvolvimento de habilidades, e são também aspectos positivamente associados com a formação dos jovens atletas (MERKEL, 2013). 
Mesmo assim, as condutas direcionadas exclusivamente para a vitória, sustentadas nas orientações de "como ganhar" e desvinculadas do conceito de "jogar melhor", são relatadas pelos treinadores entrevistados (ELENDU; DENNIS, 2017). Essas condutas afastam aspectos como o aprazimento da prática esportiva e são apontadas como um dos fatores mais influentes para que muitas crianças abandonem a prática esportiva (SIESMAA et al., 2011).

Os relatos apontam ainda que algumas adaptações regulamentares importantes para o pleno desenvolvimento dos jovens atletas (como a obrigatoriedade do uso do sistema defensivo individual, apontado anteriormente neste artigo) têm sua característica pedagógica prejudicada pelo imediatismo dos treinadores, devido a condutas que burlam os propósitos destas modificações competitivas. Ou seja, as adaptações que seriam para proporcionar um ambiente competitivo favorável são descaracterizadas para atender a necessidade de vitória imediata dos treinadores, revelando a incoerência entre a adaptação no regulamento e na prática.

Segundo Lee, Whitehead e Ntoumanis (2007), essas condutas podem resultar nas transgressões que se caracterizam como o descumprimento das adaptações do jogo de maneira vantajosa à equipe infratora, ou na obtenção de vantagens competitivas, que, apesar de não descumprirem as regras da competição, interferem diretamente no clima competitivo em favor da equipe que promove esses comportamentos. Tais condutas são capazes de influenciar profundamente a maneira como o jovem passa a compreender o cenário competitivo, influenciando-o em suas condutas e nos valores ali aprendidos (PALOU et al., 2013).

Logo, mudar as regras não parece ser tão efetivo se não estiver vinculado com a ação e consciência pedagógica do treinador. Por isso, outras propostas, que envolvam a participação ativa dos treinadores como promotores das ações necessárias para o desenvolvimento dos atletas, parecem ser mais adequadas para proporcionar situações favoráveis ao aprendizado esportivo dos atletas jovens, tais como a elaboração de um sistema de competição em que não somente o campeão tenha destaque, acampamentos de aperfeiçoamento regionais, estaduais e nacionais, entre outros.

\section{Considerações Finais}

Para os treinadores de elite entrevistados, a competição é parte integrante do processo de formação dos jovens atletas. No entanto, em categorias de base ela não pode ser sustentada apenas pelos seus fins competitivos, mas pela capacidade formativa que esse ambiente proporciona.

Os treinadores de elite do handebol apontam a necessidade de adaptações e de cuidados específicos para os jovens competirem, garantindo a permanência e a evolução desses atletas em longo prazo, de modo que a competição tem grande potencial para contribuir com a formação tática, técnica, física e psicológica desses jovens, melhorando a qualidade do processo de formação esportiva, tendo em vista a composição de equipes de handebol de elite.

Destacou-se nas entrevistas o fato de que, mesmo diante das modificações propostas nas competições de jovens, é recorrente que treinadores de categorias de base, seja por pressão para a conquista de resultados ou mesmo pelos seus próprios interesses, abdiquem dos pressupostos pedagógicos que devem orientar a formação do atleta em longo prazo para elaborar maneiras de vencer, mesmo que para isso atitudes transgressoras sejam fomentadas, destacando a necessidade de que esse seja um tema de futuros estudos em busca de novas evidências e maneiras práticas para lidar com o cenário formativo do esporte.

Tais condutas, segundo treinadores de elite, contrapõem o papel formador do esporte durante a infância e juventude e pode impactar negativamente no caminho de desenvolvimento para o alto rendimento.

Este trabalho traz indicações qualitativas sobre o processo de formação de jovens atletas nas categorias de base, com ênfase nas estruturas competitivas. No entanto, demonstra a 
necessidade de desenvolver pesquisas investigativas e aplicadas nesse campo, para que novas propostas e estruturas sejam construídas para a evolução das competições nacionais de handebol.

\section{Referências}

ARENA, S. S.; BOHME, M. T. Federações esportivas e organização de competições para jovens. Revista Brasileira de Ciência e Movimento, v.12, n. 4, p. 45-50, 2008.

BERGERON, M. F. et al. International Olympic Committee consensus statement on youth athletic development. British Journal of Sports Medicine, v.49, n.13, p.843-851, 2015.

BROWNE, T. B.; CARLSON, T. B.; HASTIE, P. A. A comparison of rugby seasons presented in traditional and sport education formats. European Physical Education Review, v.10, n.2, p.199-214, 2004.

BURTON, D.; GILLHAM, A. D.; HAMMERMEISTER, J. Competitive engineering: Structural climate modifications to enhance youth athletes' competitive experience. International Journal of Sports Science \& Coaching, v.6, n.2, p.201-217, 2011.

CHOI, H. S.; JOHNSON, B.; KIM, Y. K. Children's development through sports competition: Derivative, adjustive, generative, and maladaptive approaches. Quest, v.66, n.2, p.191202, 2014.

COB. Comitê Olímpico Brasileiro. Regulamentos Específicos. 2018. Disponível em: $<$ https://www.cob.org.br/Handlers/RecuperaDocumento.ashx?codigo=5073>. Acesso em: 04 maio 2018

CÔTÉ, J.; HAY, J. Children's involvement in sport: A developmental perspective. In: J. M. Silva and D. E. Stevens (Ed.). Psychological Foundations of Sport Boston, MA: Allyn \& Bacon, 2002. p. 484-502.

CÔTÉ, J.; FRASER-THOMAS, J. Youth involvement in sport. Sport Psychology: A Canadian Perspective, p.270-298, 2007.

CÔTÉ, J.; LIDOR, R.; HACKFORT, D. ISSP position stand: To sample or to specialize? Seven postulates about youth sport activities that lead to continued participation and elite performance. International Journal of Sport and Exercise Psychology, v.7, n.1, p.7-17, 2009.

CÔTÉ, J.; HANCOCK, D. J. Evidence-based policies for youth sport programmes. International Journal of Sport Policy and Politics, v. 8, n. 1, p. 51-65, 2016.

CRANE, J.; TEMPLE, V. A systematic review of dropout from organized sport among children and youth. European Physical Education Review, v.21, n.1, p.114-131, 2015.

DOMINGUES, M.; GONÇALVES, C. E. The role of parents in talented youth sport. Does context matter? Polish Journal of Sport and Tourism, v.20, n. 2, p.117-122, 2013. 
ELENDU, I. C.; DENNIS, M. I. Over-emphasis on winning, host-to-win and winning-at-allcost syndrome in modern sports competitions: implications for unsportsmanship behaviours of sports participants. International Journal of Physical Education, Sports and Health, v. 4, n. 5, p.104-107, 2017.

ELLIOTT, S.; PILL, S. Competitive engineering in junior Australian football: perceptions and experiences of parents, children and coaches of 9-a-side football in an Under-8 competition. South African Journal for Research in Sport, Physical Education and Recreation, v. 38, n. 1, p.43-57, 2016.

ENGEBRETSEN, L., et al. The International Olympic Committee Consensus Statement on age determination in high-level young athletes. British Journal of Sports Medicine, v.44, n.7, p. 476-484, 2010.

ESTRIGA, L.; MOREIRA, I. (2013). Proposta metodológica de ensino do andebol. In: Jogos Desportivos Coletivos-Ensinar a Jogar. Porto: Editora FADEUP, 2013, p.123-163.

FRASER-THOMAS, J.; CÔTÉ, J.; DEAKIN, J. Understanding dropout and prolonged engagement in adolescent competitive sport. Psychology of Sport and Exercise, v.9, n.5, p.645-662, 2008.

GARCÍA-ANGULO, A.; ORTEGA, E.; MENDOZA, R. Levels of satisfaction and preferences handball players in technical and tactical actions by play category. E-Balonmano. com: Revista de Ciencias del Deporte, v.10, n.3, p.139-148, 2015.

KRAHENBÜHL, T.; LEONARDO, L. O ensino do sistema defensivo individual no handebol e suas considerações para a iniciação esportiva. Pensar a Prática, v.21, n.1, p.194-206, 2018.

LEE, M. J.; WHITEHEAD, J.; NTOUMANIS, N. Development of the attitudes to moral decision-making in youth sport questionnaire (AMDYSQ). Psychology of Sport and Exercise, v.8, n.3, p.369-392, 2007.

LEONARDO, L.; SCAGLIA, A. J.; REVERDITO, R. S. O ensino dos esportes coletivos: metodologia pautada na família dos jogos. Motriz, v.15, n.2, p.236-246, 2009.

LEONARDO, L. et al. O efeito da idade relativa influencia o tempo de participação competitiva de atletas de handebol do sexo masculino com até 13 anos de idade. Retos, v.33, n.1, p.195-198, 2018.

LEONARDO, L.; SCAGLIA, A. J. Sete anos de adaptações competitivas na Federação Paulista de Handebol: um estudo documental da categoria sub-14. Motrivivência, no prelo, 2018a.

LEONARDO, L.; SCAGLIA, A. J. Study on youth handball regulations: a documental analysis on the mandatory use of individual defensive system in under -12 and under-14 competitions. Journal of Physical Education, 2018b. No prelo.

MAYRING, P. Qualitative content analysis: theoretical foundation, basic procedures and software solution. Klagenfurt, 2014. Disponível em: <http://nbnresolving.de/urn:nbn:de:0168-ssoar-395173>. 
MARQUES, R. F. R.; DE ALMEIDA, M. A. B.; GUTIERREZ, G. L. Esporte: um fenômeno heterogêneo: estudo sobre o esporte e suas manifestações na sociedade contemporânea. Movimento, v.13, n.3, p.225-242, 2007.

MATTHYS, S. P. J. et al. The contribution of growth and maturation in the functional capacity and skill performance of male adolescent handball players. International Journal of Sports Medicine, v.33, n.7, p.543, 2012.

MERKEL, D. L. Youth sport: Positive and negative impact on young athletes. Open Access Journal of Sports Medicine, v.4, n.1, p.151, 2013.

MENEZES, R. P. The system of defensive teaching of handball: methodological considerations on cadet category. Pensar a Prática, v.13, n.1, p.1-13, 2010.

MENEZES, R.P.; REIS, H. H. B.; TOURINHO FILHO, H. Ensino-aprendizagemtreinamento dos elementos técnico-táticos defensivos individuais do handebol nas categorias infantil, cadete e juvenil. Movimento, v.21, n.1, p.261-273, 2015.

MENEZES, R. P.; MARQUES, R. F. R.; NUNOMURA, M. O ensino do handebol na categoria infantil a partir dos discursos de treinadores experientes. Movimento, v.21, n.2, p.463477, 2015.

MILISTETD, M. et al. Concepções dos treinadores acerca do papel da competição na Formação desportiva de jovens jogadores de voleibol. Journal of Physical Education, v.19, n.2, p.151-158, 2008.

MILISTETD, M. et al. Analysis of the Competitive Organization of Sports for Children and Youths Structural and Functional Adaptations. Revista Brasileira de Ciências do Esporte, v.36, n.3, p.671-678, 2014.

PALOU, P. et al. Acceptance of gamesmanship and cheating in young competitive athletes in relation to the motivational climate generated by parents and coaches. Perceptual and motor skills, v.117, n.1, p.290-303, 2013.

SCAGLIA, A. J.; REVERDITO, R. S.; GALATTI, L. Ambiente de jogo e ambiente de aprendizagem no processo de ensino dos jogos esportivos coletivos: desafios no ensino e aprendizagem dos jogos esportivos coletivos. Jogos desportivos: formação e investigação. Florianópolis: UDESC, p.133-170, 2013.

SCAGLIA, A. J. Pedagogia do Jogo: O processo organizacional dos Jogos Esportivos Coletivos enquanto modelo metodológico para o ensino. Revista Portuguesa de Ciências do Desporto, v.17(S1A), p. 27-38, 2017.

SIESMAA, E. et al. Factors that are most influential in children's continued and discontinued participation in organised sport: The role of sport injury and injury risk perceptions. In: Antony D. Farelli (Ed.). Sport Participation: Health Benefits, Injuries and Psychological Effects. Nova Science Publishers, New York, United States, p. 47-84, 2011. 
THOMAS, G. L.; WILSON, M. R. Playing by the rules: a developmentally appropriate introduction to rugby union. International Journal of Sports Science \& Coaching, v. 10, n.2-3, p.413-423, 2015.

WERNER, P.; THORPE, R.; BUNKER, D. Teaching games for understanding: Evolution of a model. Journal of Physical Education, Recreation \& Dance, v.67, n.1, p.28-33, 1996.

WIERSMA, L. D. Reformation or reclassification? A proposal of a rating system for youth sport programs. Quest, v.57, n.4, p.376-391, 2005.

Recebido em: 21/05/2018

Revisado em: 31/08/2018

Aprovado em: 14/09/2018

Endereço para correspondência:

tathykrahenbuhl@ufg.br

Tathyane Krahenbühl

Faculdade de Educação Física e Dança

Universidade Federal de Goiás

Campus Samambaia

Avenida Esperança S/n, Campus Samambaia

74.690-900 Goiânia - Goiás - Brasil 